\title{
VALORES RESTAURATIVOS APLICAVÉIS AO SISTEMA JURÍDICO CRIMINAL BRASILEIRO
}

\begin{abstract}
Renata Matos ${ }^{1}$
Resumo: Este artigo é um estudo pautado na possibilidade de implementação da Justiça Restaurativa no Brasil. Realiza-se uma breve abordagem sobre a forma de punir do Estado, em detrimento ao inexpressivo controle criminal, como também se investiga dispositivos legais penais impostos pelo ordenamento jurídico atual, que poderiam servir para procedimentos restaurativos.

Palavras-chave: Sistema de Justiça do Brasil. Dispositivos jurídicos penais. Justiça Restaurativa.
\end{abstract}

\section{INTRODUÇÃO}

Ao abordar a justiça restaurativa como um sistema alternativo ou complementar ao ordenamento jurídico brasileiro, é necessário refletir sobre a segurança e a proteção que a sociedade clama todos os dias diante do crescente índice de violência. Neste sentido, a necessidade de segurança dos cidadãos não é somente uma necessidade de proteção contra a criminalidade, mas também a necessidade de estarem e sentirem-se garantidos no exercício de todos os seus plenos direitos.

Por conta disso, a justiça restaurativa retira o infrator do protagonismo, tornando a vítima parte atuante e indispensável na realização de um acordo restaurativo, a desenvolver o direito de expressar-se, assim como o direito de satisfazer suas necessidades emocionais, buscando a prevenção da criminalidade. É

1 Aluna da Escola Superior da Magistratura do Estado de Santa Catarina (ESMESC). Bacharela em Direito pela Universidade do Sul de Santa Catarina - UNISUL; Especializanda em Direito Público pela parceria FURB/ESMESC. Juíza Leiga. E-mail: renatamatos1@live.com 
uma nova percepção de Justiça, que busca restaurar a relação do infrator com a vítima, juntamente com ressarcimento das perdas materiais e psicológicas sofridas por todos aqueles que foram atingidos.

Esta pesquisa busca verificar a problemática da possibilidade e efetividade da implementação da justiça restaurativa no Brasil, com o objetivo de analisar as dificuldades atuais da justiça convencional em contraposição à compatibilidade dos procedimentos restaurativos no atual sistema penal brasileiro.

Para tanto, reservou-se um tópico ao Sistema de Justiça aplicado no ordenamento jurídico brasileiro, caracterizando a forma de punir do Estado e as conseqüências dessa punição ao infrator e à sociedade, em razão da crescente criminalidade presente e do péssimo estado carcerário brasileiro.

Na seqüência, um apanhado conceitual da justiça restaurativa, que demonstra mais algumas concepções sobre os procedimentos restaurativos do que propriamente uma definição, haja vista não haver termo e conceito únicos. Ademais, serão estabelecidos os dispositivos da legislação brasileira relacionados a práticas restaurativas, abordando a questão do lugar da justiça restaurativa em relação à justiça criminal, com o objetivo de identificar artigos compatíveis com os procedimentos restaurativos.

Este artigo propõe um comparativo da justiça criminal terapêutica com a restaurativa, a fim de examinar os valores restaurativos que poderão ser realizados de forma prática no ordenamento jurídico.

\section{SISTEMA DE JUSTIÇA NO BRASIL}

Inicialmente far-se-á uma abordagem acerca da forma em que é promovida a punição pelo Estado aos autores de infrações penais. Em seguida, mostrar-se-á a realidade criminal que aflige a sociedade e ainda, se a justiça é eficientemente aplicada a todos os indivíduos em razão desse quadro. Prosseguindo, será 
abordada a situação carcerária brasileira, bem como as condições precárias onde o preso cumpre pena e, por fim, as alternativas aplicadas à substituição da pena de prisão pelo atual regime penal.

\subsection{Forma de Punir}

De acordo com Guilherme de Souza Nucci², a sanção imposta pelo Estado ao criminoso, por meio de ação penal, existe com a finalidade de retribuição ao delito perpetrado e à prevenção a novos crimes.

Por sua vez, Costa Jr. ${ }^{3}$ entende que o direito de punir do Estado é aquele denominado como direito subjetivo, podendo apenas o Estado exercê-lo. Argumenta também, que este possui função de império, submetendo o réu ao processo e à pena, nos limites definidos pelo direito, para assegurar a convivência social.

Neste sentido, o direito penal positivo constitui-se do conjunto de preceitos legais que regulam a atividade soberana estatal, definindo os crimes e cominando as respectivas sanções. Por turno, o direito estatal subjetivo emerge do próprio direito penal objetivo, constituindo-se no ius puniendi, cuja titularidade exclusiva pertence ao Estado, como manifestação do seu poder de império. Assim, o direito de punir do Estado, isto é, o direito penal subjetivo, é limitado pelo próprio direito penal objetivo, que lhe dá limites e assegura a efetivação do direito constitucional de liberdade a todos os indivíduos.

Conclui Michel Foucault ${ }^{4}$, que para punir é preciso ajustar a enormidade da pena e a enormidade da falta aos seus próprios efeitos, calculando uma pena em função não do crime, mas de sua possível repetição. Visar não à ofensa passada, mas à

\footnotetext{
$2 \mathrm{NUCCl}$, Guilherme de Souza. Manual de Direito Penal - Parte Geral - Parte Especial. 6 ed. São Paulo: Editora Revista dos Tribunais, 2009. p. 379.

3 COSTA JR., Paulo José. Curso de Direito Penal. 1. ed. São Paulo: Saraiva, 2009. p. 302. 4 FOUCAULT, Michel. Tradução da Raquel Ramalhete. Vigiar e Punir - Nascimento da prisão. 20. ed. Petrópolis: Vozes, 1999. p. 48.
} 
desordem futura, fazendo que o infrator sinta-se com isso desestimulado a recomeçar.

Afirmando isso, Foucault acrescenta que o motivo do crime é a vantagem que se representa com ele e a eficácia da pena está na desvantagem que se espera dela. Não devendo assim, ser por meio de dor o instrumento da técnica punitiva, mas sim com a quantidade de pena que o crime merece ser punido.

Logo, o Estado age coibindo determinadas condutas, criando na verdade, um clima propício não só para tais condutas se proliferarem, como também para que outras atividades criminosas vicejem. Exemplo disso é a política de repressão ao jogo do bicho e ao tráfico ilícito de drogas, pois, de um lado se o direito penal não inibisse tais comportamentos, por outro, ao condená-los à clandestinidade, torna-os extremamente atraentes em razão do resultado financeiro que cada um pode resultar, a estabelecer, entre os seus exploradores, uma concorrência violenta e sanguinária.

Assim, a criminalidade é um problema de todos e que não será resolvido com o simples dilema "Lei e Ordem", o qual representa uma política criminal repressiva e defensora, intransigente da ordem, quase sempre estabelecida injustamente. Além disso, os meios de comunicação coletiva apresentam a criminalidade como um "perigoso inimigo" interior, nessas condições fica difícil a sociedade abandonar a atitude predominantemente repressiva e vingativa.

Dessa forma, é indispensável uma transformação radical da opinião pública e da atitude de cidadãos em relação ao delinqüente, caso realmente haja a intenção em oportunizar-lhe a ressocialização.

Em contrapartida, Vera Regina Pereira de Andrade ${ }^{5}$, afirma que o desvio da criminalidade não é uma qualidade intrínseca à reação (ou controle) social, mas uma qualidade (etiqueta) atri-

5 ANDRADE, Vera Regina Pereira de. A llusão de Segurança Jurídica: do controle da violência à violência do controle penal. Porto Alegre: Livraria do Advogado, 1997. p. 203-204. 
buída a determinados sujeitos, por meio de complexos processos de interação social.

Hoje, o máximo que o sistema prisional representa é um invólucro para separar aqueles que transcenderam os limites dos demais. Os noticiários indicam cada vez mais como o sistema prisional brasileiro está saturado, superlotado e absolutamente sem esperança de mudanças em um futuro próximo. Acredita assim, que o aparelho penal vigente, em relação às penas, ainda está funcional.

O sistema penitenciário atual é inspirado no modelo utilizado por mosteiros antigos como penitenciária pela expiação, isto é, o monge se enclausurava e se isolava dos demais para se retirar e meditar sobre a conduta danosa que cometera. Este local tinha como objetivo fazer pensar e visualizar o erro para que não se tornasse a cometê-lo, e ainda, era visto como uma reparação à sociedade e como proteção aos demais indivíduos pelo infrator, pois estaria distante desses e sofrendo uma pena pela conduta que praticara.

Tal conceito fora adaptado e incorporado à sociedade moderna e reflete exatamente o sistema penal adotado para os criminosos. Contudo, ao invés de ter um espaço para se arrepender, o infrator obtém um "cursinho" do crime, no qual tem verdadeiras aulas de aprimoramento em práticas danosas, propiciando a este uma gama de novas formas delitiva, que poderão ser aplicadas após a sua liberdade. Logo, perdendo o caráter inicial de aplicação da pena como finalidade social e ressocializante.

Atualmente, a prisão está representando um prejuízo à sociedade em si, ao próprio Estado e como também para o próprio preso, deixando qualquer intenção em se arrepender e dividindo a cela com cinqüenta criminosos, onde era para ser vinte. Destarte, retirar-se-á o indivíduo do convívio social, em razão do cometimento do delito, por outro lado, como já explanado, proporcionará ao delinqüente um grande aperfeiçoamento de seus dotes criminais, e ainda que não os tenha, terá a chance em adquiri-los. 
Neste sentido, revela-se a incoerência e insensatez do atual sistema penal e expõe a questão de maneira definitiva: "Paradoxalmente, quanto mais o cárcere demonstra-se falido, mais aumenta a demanda”.

O sistema penitenciário enfrenta uma crise tão elevada, que, presentemente, muitos presos praticam atividades criminosas dentro do presídio, por meio de visitas, telefones celulares e outros meios tecnológicos. Propiciando assim, maior tranqüilidade ao detento para cometer outros crimes, ainda que preso, porque assim está isolado da sociedade, logo, está "protegido" dos seus inimigos.

Apesar disso, afirma Gonçalves ${ }^{6}$, que não se descobriu um meio alternativo, ou mais eficiente, de tratar os infratores da lei penal condenados às infrações graves. Destarte, para as de menor potencial ofensivo, foram instituídas medidas alternativas à prisão, como a multa e as penas restritivas de direito.

No ponto de vista de Cesar Roberto Bitencourt ${ }^{7}$, a lei n. 7.029/84 reformulou toda a Parte Geral do Código de 1940, humanizando as sanções penais e adotando penas alternativas à prisão, além de reintroduzir no Brasil o festejado sistema diasmulta. Além disso, acredita que, embora os melhores elencos de alternativas à pena privativa de liberdade estejam no nosso país, a falta de vontade política governamental tornou inviável sua aplicação fiel, já que não são dotadas de infra-estrutura no sistema penitenciário em quase toda totalidade.

\section{JUSTIÇA RESTAURATIVA NO ORDENAMENTO JURÍDICO BRASILEIRO}

O pesquisador Albert Eglash é apontado como o primeiro a ter empregado a expressão "Justiça Restaurativa” em um texto de 1977 intitulado "Beyond Restitution: Creative Restitution".

6 SALIBA, Marcelo Gonçalves. Justiça Restaurativa e paradigma punitivo. Curitiba: Juruá, 2009. p 180.

7 BITENCOURT, Cezar Roberto. Tratado de Direito Penal - Parte Geral 1. 14. ed. São Paulo: Saraiva, 2009. p. 205 
No entanto, como descreve Marcos Rolim ${ }^{8}$, as práticas restaurativas são muito antigas, alicerçadas em tradições de muitos povos do oriente e do ocidente.

A justiça restaurativa, como prática comunitária, é primitiva, remontando aos códigos de Hamurabi, Ur-Nammu e LipitIshtar há cerca de dois mil anos antes de Cristo. De acordo com Mariana Marinho Barbalho Tavares, a justiça restaurativa foi implantada inicialmente na Nova Zelândia, em 1995 e em seguida em outros países como o Canadá, a Austrália, a África do Sul, o Reino Unido e a Argentina.

As práticas restaurativas ressurgiram com as primeiras experiências contemporâneas, por meio de mediação entre infrator e vítima, colocadas em prática nos anos 70. A experiência neozelandesa, baseada nas tradições maoris, ampliou esses encontros, participando familiares, em caso de infratores adolescentes e pessoas da comunidade, em caso de infratores adultos.

A Justiça Restaurativa não é desenhada para eliminar a função estatal ou, tampouco, para substituíla. Como determina Saliba ${ }^{9}$ a inafastabilidade da atividade jurisdicional é princípio fundamental em um Estado Democrático de Direito, mantendo-se as garantias contra o poder punitivo.

Neste sentido, deve-se coadunar a justiça tradicional com a da Restaurativa, não eliminando a primeira, apenas revisando-a. Por isso, há a importância na geração de programas restaurativos antes, durante e depois de iniciado o processo judicial, pois assim, estes programas permitirão prevenir futuros fatos delituosos e controlarão, em grande medida, a violência que se gera pelo crime.

É exatamente o que será apresentado adiante.

8 ROLIM, Marcos. Justiça restaurativa: para além da punição. 2007. Disponível em: <http://www.comunidadesegura.org/files/active/0/Marcos_Rolim_Justica_Restaurativa.pdf>. Acesso em 17 maio 2010.

9 SALIBA, Marcelo Gonçalves. Justiça Restaurativa e paradigma punitivo. Curitiba: Juruá, 2009. p 181. 


\subsection{Estatuto da Criança e do Adolescente (Lei n. 8.069/90)}

De início, é relevante abordar que a justiça restaurativa foi originariamente criada para restaurar os conflitos relativos à criança e ao adolescente. Tanto é assim, que o estatuto da criança e juventude criou alguns institutos no ordenamento jurídico, dentre os quais a remissão, pela qual possibilita a exclusão, suspensão ou extinção do processo.

O Estatuto da Criança e do Adolescente sugere implicitamente o uso do modelo restaurativo, em vários dispositivos, particularmente sobre a remissão (art. 126) e as medidas sócioeducativas previstas no art. 112 e seguintes do diploma legal.

Além disso, o art. 126 da lei n. 8.069/90 não só cuida da remissão, como também da exclusão, suspensão ou extinção do processo referente à aplicação de medidas sócio-educativas a adolescentes. Neste sentido, o caput deste artigo permite a proposta de remissão pelo representante do Ministério Público, requerendo a exclusão do processo, e pelo Juiz de Direito, como meio de suspensão ou extinção do procedimento (arts. 126, parágrafo único, e 186, § 1\%).

De forma geral, as medidas sócio-educativas acumuladas com medidas protetivas, pertencentes à justiça restaurativa, servirão de grande importância aos problemas relacionados à criança e ao adolescente, direcionando-as à causa (tratamentos contra drogas, álcool, etc) ou como também suas reinclusões à sociedade, na medida em que são condicionados ao aproveitamento, à freqüência na escola, aos cursos profissionalizantes, entre outros.

A experiência de muitos países que adotaram práticas restaurativas tem mostrado serem elas extremamente eficazes no trato de adolescentes infratores. No Brasil, a legislação aplicável para menores de 18 anos que cometam fatos definidos como infrações penais é o Estatuto da Criança e do Adolescente (Lei n. 8.069, de 13 de julho de 1990). 
Juan Carlos Vezzulla ${ }^{10}$ aborda sobre a experiência ocorrida em um projeto inserido no fórum de Joinville, Santa Catarina, coordenado pelo Juiz Alexandre Morais da Rosa, em que foi construído um modelo operacional com desenvolvimento para implantação no Brasil, por meio de mediação, no qual os adolescentes em conflito com a lei pudessem trabalhar sua situação.

Primeiramente, abrandaria, conforme Vezzulla ${ }^{11}$, entender as características especiais do adolescente em uma abordagem psicossocial e legal, segundo, apresentar as características da mediação de conflitos a partir de trabalhos às partes, buscando atender aos fatores intervenientes na conduta transgressora do adolescente e também às indicações do Estatuto da Criança e do Adolescente. Por último, proporcionar um desenho de serviço integral de mediação com adolescentes autores de ato infracional no Brasil, a fim de elaborar e incorporar positivamente sua situação, com todos os direitos escritos na Constituição e no Estatuto da Criança e do Adolescente.

Como descrito por Alexandre Morais da Rosa, os resultados são animadores. Em um dos casos,

o adolescente, entendeu a transcendência do seu ato de furtar um "mouse" de um computador, pode se desculpar com o proprietário e elaborar seu fantasma, além de reelaborar seu lugar na família. Nesta aproximação, ele promoveu uma ressignificação da conduta e foi via círculo restaurativo que o ato foi superado. [...]. ${ }^{12}$

Logo, com mesma compreensão e diálogo que a família deverá suportar o adolescente que prova as suas capacidades e limites, também assim deverá agir a sociedade e o Estado quando um adolescente é autor de ato infracional. O Esta-

10 VEZZULLA, Juan Carlos. A mediação de conflitos com adolescentes autores de ato infracional. Florianópolis: Habitus, 2006. p. 26.

11 Idem.

12 ROSA, Alexandre Morais da. Revista IOB de direito penal e processo penal. Porto Alegre, ano 9, n. 50., jun/jul-2008. p. 212. 
tuto da Criança e do Adolescente (Art. 98; 99; 100; 101; 106; 107; 110; 111, todos da Lei n. 8.609/90) é claro a respeito dos cuidados diferenciais que merecem ser tomados e os objetivos que precisam ser atingidos pela sociedade, pela polícia, pelo Ministério Público e pelo Poder Judicial.

Marli Marlene Moraes da Costa e Rosane Teresinha Carvalho Porto $^{13}$ tecem algumas considerações sobre a necessidade de abandonar os paradigmas baseados em uma educação repressora ou em uma justiça punitiva que tem por premissa amestrar e domesticar crianças e adolescentes. Assim, a Justiça Restaurativa vem buscar a emancipação desses como atores sociais aliados a política dialógica intersubjetiva.

Neste contexto, a importância da função social do juiz e do Judiciário em possibilitar e conclamar que a comunidade, juntamente com outros segmentos que trabalham com os adolescentes, debata sobre os caminhos que devam ser reconstruídos para que a violência não vitimize mais suas crianças e adolescentes.

Neste sentido, deve-se acreditar em novas formas de engajamento ao laço social, porque se isto não ocorrer, na seara da infância e juventude, entregar-se-á o bilhete da imputabilidade, deixando-o à mercê do sistema penal.

\subsection{Lei dos Juizados Especiais Criminais (Lei n. 9.099/95)}

Outro ensinamento pátrio que possibilita a utilização da justiça restaurativa é a Lei n. 9.099/95, eis que, com ela, houve a criação de institutos jurídicos e procedimentos que ensejam a adoção do referido sistema.

Sob a mesma linha, com as inovações da Constituição de 1988 e o advento, principalmente, da Lei 9.099/95, abre-se uma pequena janela, no sistema jurídico do Brasil, ao princípio da oportunidade, permitindo certa acomodação sistêmica do

13 COSTA, Marli Marlene Moraes da; PORTO, Rosane Teresinha Carvalho. Revista da Ajuris - Associação dos Juízes do RS. Porto Alegre, ano 35. n. 110, jun 2008. p. 298-299. 
modelo restaurativo em nosso país, mesmo sem mudança legislativa. A Constituição prevê,

no art. 98, I, a possibilidade de conciliação em procedimento oral e sumaríssimo, de infrações penais de menor potencial ofensivo.

Art. 98. A União, no Distrito Federal e nos Territórios, e os Estados criarão:

I. Juizados especiais, providos por juízes togados, ou togados e leigos, competentes para a conciliação, o julgamento e a execução de causas cíveis de menor complexidade e infrações penais de menor potencial ofensivo, mediante os procedimentos oral e sumaríssimo, permitidos, nas hipóteses previstas em lei, a transação e o julgamento de recursos por turmas de juízes de primeiro grau; ${ }^{14}$

A fase preliminar prevista no art. 70 e 72 a 74, da lei 9.099/95, pode ter a forma restaurativa, o qual produz:

Da Fase Preliminar

Art. 70. Comparecendo o autor do fato e a vítima, e não sendo possível a realização imediata da audiência preliminar, será designada data próxima, da qual ambos sairão cientes.

Art. $71 \ldots$

Art. 72. Na audiência preliminar, presente o representante do Ministério Público, o autor do fato e a vítima e, se possível, o responsável civil, acompanhados por seus advogados, o Juiz esclarecerá sobre a possibilidade da composição dos danos e da aceitação da proposta de aplicação imediata de pena não privativa de liberdade.

Art. 73. A conciliação será conduzida pelo Juiz ou por conciliador sob sua orientação.

14 PINTO, Renato Sócrates Gomes. Justiça restaurativa: o paradigma do encontro. Disponível em: <http://jus2.uol.com.br/doutrina/texto.asp?id=10238>. Acesso em: 14 maio 2010. p. 29. 
Parágrafo único. Os conciliadores são auxiliares da Justiça, recrutados, na forma da lei local, preferentemente entre bacharéis em Direito, excluídos os que exerçam funções na administração da Justiça Criminal.

Art. 74. A composição dos danos civis será reduzida a escrito e, homologada pelo Juiz mediante sentença irrecorrível, terá eficácia de título a ser executado no juízo civil competente.

Parágrafo único. Tratando-se de ação penal de iniciativa privada ou de ação penal pública condicionada à representação, o acordo homologado acarreta a renúncia ao direito de queixa ou representação. ${ }^{15}$

Os dispositivos acima permitem ao juiz oportunizar a possibilidade de composição dos danos e da aceitação da proposta de aplicação imediata de pena não privativa de liberdade (art. 72), num procedimento que pode ser conduzido por um conciliador. Se presentes os pressupostos de admissibilidade do processo restaurativo, sob o ponto de vista jurídico (requisitos objetivos e subjetivos a serem definidos em consonância com a lei penal), em determinado caso, poderá ser encaminhado ao Núcleo de Justiça Restaurativa para avaliação multidisciplinar, dirigindo-se sobre sua viabilidade técnica, e com isso, avançando nas ações preparatórias para o encontro restaurativo.

Releva destacar que um ponto que pode ensejar controvérsia, nos casos previstos no art. 74, caput, da Lei do Juizado Especial, importa em renúncia ao direito de queixa ou representação nos casos de crime de ação penal privada ou pública condicionada. No entanto, para esses casos, não há nenhum impedimento legal para a proposta de encaminhamento ao procedimento restaurativo, desde que a vítima seja informada de maneira clara de que o acordo importará em renúncia ao direito de queixa ou representação, restando-lhe apenas a busca da reparação cível negociadaOutra janela para a alternativa restaurativa é o instituto da suspensão do processo (art. 89, da Lei n.

15 Idem. 
9.099/95), por meio do qual pode o processo ficar suspenso, de dois a quatro anos, desde que o infrator sujeite-se a algumas condições previstas em lei e logo, preencha os requisitos por ela estabelecidos. Em algumas situações, sem que conciliador, juiz ou membro do Ministério Público, aplique friamente a lei, poderia incluir métodos restaurativos, assim, o autor do delito reconhecendo o erro cometido, adotaria uma nova postura para voltar a viver pacificamente em comunidade.

Também nos crimes contra idosos, o processo restaurativo é possível, por força do art. 94, da Lei n. 10.741/03 - o Estatuto do Idoso - que prevê procedimento da Lei 9.099/95 para crimes contra idosos cuja pena privativa de liberdade não ultrapasse 4 anos.

Vale destacar, quando concluído o procedimento restaurativo no núcleo, o caso deverá ser retornado ao Ministério Público, com um relatório e um acordo restaurativo escrito e subscrito pelos participantes. A Promotoria incluiria as cláusulas ali inseridas na sua proposta, para homologação judicial, e se passaria, então, à fase executiva, com o acompanhamento integral do cumprimento do acordo, inclusive para monitoramento e avaliação do programa.

As diferenças entre a justiça restaurativa e o Juizado Especial Criminal são inúmeras, não obstante, acredita ser fundamental a pretensão da restaurativa em incrementar não o exercício do poder punitivo, e sim o acesso à justiça de qualidade. Destaca Raffaella o ensinamento de Sica, segundo o qual acredita ser isso possível, em razão da cisão do sistema penal

num quadro de dupla entrada (mediação e punição), o qual poderá, em tese, diminuir tanto o numero de castigos impostos, quando a cifra negra, oferecendo resposta institucional mais acessível e viável para um série de conflitos que ficaram marginalizados ou não encontraram respostas satisfatórias dentro de um sistema de mão única, fechado e inflexível. ${ }^{16}$

16 SICA apud, PALLAMOLLA, Raffaella da Porciúncula. Justiça restaurativa: da teoria à prática. São Paulo: IBCCRIM, 2009. p. 151. 
Neste sentido, conclui-se que com vontade política e treinamento de pessoal especializado, a par de uma conscientização dos agentes estatais envolvidos no processo, poderá talvez ser possível a utilização de Juizados Criminais Especiais como porta de entrada para a Justiça Restaurativa no Brasil.

\subsection{Código Penal}

O Código Penal brasileiro é de 1940 e alterado por diversas leis posteriores, destacando-se a criação das penas restritivas de direitos em 1984. Depois, em 1998, por meio da Lei n. 9.714, ampliou-se os sistemas de penas alternativas, admitindo sua utilização em maior número de infrações penais (crimes dolosos e culposos, cuja pena não ultrapasse quatro anos, cometidos sem violência ou grave ameaça à pessoa), como também se aumentou a quantidade de penas restritivas de direitos.

Há alguns institutos jurídicos como constituintes às práticas parcialmente restaurativas, dentre as quais: prestação pecuniária (art. 45, § 1º do Código Penal), em que trata do pagamento de uma quantia em dinheiro à vítima ou seus dependentes; prestação inominada (art. 45, § 2 ${ }^{\circ}$, do CP), para este caso havendo concordância do beneficiário (vítima, dependente, entidade publica ou privada com destinação social), poderá ser substituída por prestação de outra natureza (cesta básica, mão-de-obra, reposição de árvores, etc.). Outros também conferem a perda de bens e valores (art. 45, § $3^{\circ}$, do CP), prestação de serviços à comunidade ou entidade pública (art. 46, § 2º, do CP), interdições temporárias de direitos (art. 47 do CP) e limitação de fim de semana (art. 48, do CP).

Do mesmo modo, há outros regramentos do Código Penal que poderão ser efetivamente aplicados de acordo com a Justiça Restaurativa, dentre os quais: arrependimento posterior (art. 16, do CP), interdição temporária de direitos (art. 47, do CP), sursis especial (art. 78, § 2º, do CP), reabilitação criminal (art. 94, III, do CP), entre outros. 
Percebe-se que na tradicional justiça penal, o acusado fica adstrito a um breve "interrogatório" sobre os termos da denúncia. Assim, a versão do acusado (sobre fato tão relevante em sua vida e na vida de outras pessoas) torna-se reduzida a algumas dezenas de linhas de uma folha de papel. Isso acaba desobrigando o acusado de uma mais sincera percepção sobre sua própria conduta, provocando um distanciamento que não o compromete psicologicamente e eticamente com a natureza e as finalidades do procedimento judicial de que participa.

Com efeito, o afastamento do acusado das conseqüências dos seus atos, no modelo tradicional, tem favorecido a construção de estratégias psicológicas defensivas, em que a confissão do erro (primeiro passo para a sua superação) se transforma em vitimização do próprio acusado, preferindo responsabilizar a vítima, o sistema jurídico, o advogado, as condições sociais, familiares, econômicas, etc.

Evidentemente que o modelo restaurativo só será possível se houver concordância das partes envolvidas, em busca de soluções, visto que se o acordado for descumprido, o procedimento atualmente adotado passaria a ser o adequado. No dizer de Tavares ${ }^{17}$, esse processo complementar a justiça atual busca uma solução mais demorada talvez, contudo, mais eficiente para a grande maioria de casos de violência, causados principalmente por problemas pessoais, e, em grande maioria por certas necessidades que não justificam o ato, mas o torna corriqueiro.

Assim, felizmente, se falharem o juiz, o promotor e o advogado, o sistema assegura sempre ao prejudicado o acesso ao judiciário, conforme previsto no art. 5, XXXV, da Constituição Federal, para que assim haja a reparação da lesão ou ameaça de lesão ao direito. Logo, tanto a vítima, quanto o infrator, inclusive por meio de advogados, como também o Ministério Público, de ofício ou a requerimento da parte, poderá questionar o acordo

17 TAVARES, Mariana Marinho Barbalho. Revista do Ministério Público do estado do Rio Grande do Norte. Natal, ano 5. n. 7, julh/dez - 2005. p. 140. 
restaurativo em juízo, caso manifestamente carente de requisitos essenciais de existência, validade ou eficácia.

\section{CONCLUSÃO}

Diante do exposto, pode-se inferir que a implantação da Justiça restaurativa (JR) ainda apresenta-se em lento processo no Estado brasileiro. Portanto, o assunto merece abordagem mais ampla e esclarecimentos mais efetivos aos operadores de direito, como também a toda sociedade.

Contudo, enquanto as alterações político-criminais por uma justiça melhor e mais eficiente crescem em ordem aritmética, a violência tem crescido geometricamente. Assim, faz-se perceber a inoperância do atual sistema de justiça brasileiro no controle da criminalidade, pois o meio carcerário parece hoje um espaço mais propício a fomentar a delinqüência do que a promover a reintegração do preso.

Além disso, os meios de comunicação colaboram para perpetuar a idéia de que o "inimigo" deve ser combatido por meio predominantemente repressor e vingativo. Desta forma, a maioria da população brasileira acredita que, com mais intervenção, leis, juízes, prisões, estará mais segura dos infratores, esquecendo, no entanto, que tais medidas não implicarão menos delitos. Logo, a falência dos termos de medidas retributivas e preventivas demanda a busca de alternativas para a pena privativa de liberdade.

É justamente pela constatação desta falência que a justiça restaurativa surgiu, com ação de movimentos sociais que se preocupavam em encontrar alternativas para o atual sistema, que, inoperante e fracassado, nunca possibilitou a escuta e a efetiva reparação do dano entre as partes envolvidas no conflito. O objetivo da justiça restaurativa é, pelo menos em tese, possibilitar um espaço de escuta entre os atores sociais (infrator, vítima e comunidade), para aumentar a participação e a recuperação da vítima. A intenção da prática restaurativa é fazer com que 
os agressores assumam a responsabilidade por seu comportamento, incentivando um aprendizado a partir desta conduta, e ainda, buscando a participação de membros da comunidade na criação de uma resposta justa ante o crime.

Cabe ainda notar que a justiça restaurativa foi originariamente criada para restabelecer os conflitos relativos à criança e ao adolescente. Tanto é verdade, que alguns institutos da Lei n. 8.069/90 possibilitam a utilização de práticas restaurativas, dentre as quais a remissão, que possibilita a exclusão, suspensão ou extinção do processo por meio de medidas sócio-educativas acumuladas com medidas protetivas. $\mathrm{O}$ benefício desta prática é a resolução de problemas de crianças e adolescentes, relacionados à causa do delito (tratamentos contra drogas, álcool, etc.), pela reintegração à sociedade.

Outro dispositivo legislativo brasileiro que possibilita a utilização da justiça restaurativa é a Lei n. 9.099/95. Com ela, houve a criação de institutos jurídicos e procedimentos que ensejam a adoção deste sistema. Um exemplo claro é quando se permite ao juiz oportunizar a possibilidade de composição dos danos e da aceitação da proposta de aplicação imediata de pena não privativa de liberdade, por meio de um procedimento que pode ser conduzido por um conciliador. Desta forma, presentes os pressupostos de admissibilidade do processo restaurativo e a viabilidade técnica, é possível avançar nas ações preparatórias para o encontro restaurativo.

Há também, no arsenal do código penal, alguns institutos jurídicos relacionados às práticas parcialmente restaurativas, dentre os quais estão as penas alternativas. No entanto, não há estudos quanto a crimes de maior grau de violência no Brasil.

A maior barreira para que os operadores de direito implementem a justiça restaurativa no ordenamento jurídico é cultural, já que a sociedade brasileira só acredita na punição quando há prisão. Logo, além de ser desconhecida pela maioria da população e pelos operadores de direito, a justiça restaurativa enfrenta o desafio de acompanhar as transformações mais 
recentes no direito em geral e conter o desenvolvimento do direito penal na sua vertente repressiva. Desta forma, o sistema restaurativo representa ainda uma filosofia para atender ao conflito penal, um esquema de pensamento e estratégias para colocar em prática, ao invés de representar uma prática jurídica efetiva.

Embora seja cedo para tirar algumas conclusões sobre o modelo de justiça restaurativa, é possível afirmar que a utilização deste em sua integralidade não se faz possível no Brasil. No entanto, este modelo poderá servir como caminho para uma real mudança na justiça criminal e como uma vertente na transformação de um ambiente mais inclusivo e justo.

Abstract: This article is a study based on the possibility of implementing restorative justice in Brazil. If briefly addresses state punishment, regardless of the ineffective crime control, as well as investigates the penal provisions imposed by the current judicial order that could serve for restorative procedures.

Keywords: Brazilian Justice System. Penal provisions. Restorative Justice.

\section{REFERÊNCIAS}

ANDRADE, Vera Regina Pereira de. A Ilusão de Segurança Jurídica: do controle da violência à violência do controle penal. Porto Alegre: Livraria do Advogado, 1997.

BITENCOURT, Cezar Roberto. Tratado de Direito Penal - Parte Geral 1. 14. ed. São Paulo: Saraiva, 2009.

COSTA, Marli Marlene Moraes da; PORTO, Rosane Teresinha Carvalho. Revista da Ajuris - Associação dos Juizes do RS. Porto Alegre, ano 35. n. 110, jun -2008.

COSTA JR., Paulo José. Curso de Direito Penal. 1. ed. São Paulo: Saraiva, 2009. 
FOUCAULT, Michel. Tradução da Raquel Ramalhete. Vigiar e Punir Nascimento da prisão. 20. ed. Petrópolis: Vozes, 1999. p. 48.

NUCCI, Guilherme de Souza. Manual de Direito Penal - Parte Geral - Parte Especial. 6 ed. São Paulo: Editora Revista dos Tribunais, 2009.

PALLAMOLLA, Raffaella da Porciúncula. Justiça restaurativa: da teoria à prática. São Paulo: IBCCRIM, 2009.

PINTO, Renato Sócrates Gomes. Justiça restaurativa: o paradigma do encontro. Disponivel em: <http://jus2.uol.com.br/doutrina/texto.asp?id=10238>. Acesso em: 14 maio 2010.

ROLIM, Marcos. Justiça restaurativa: para além da punição. 2007. Disponível em: <http://www.comunidadesegura.org/files/active/0/Marcos_Rolim_ Justica_Restaurativa.pdf $\gg$. Acesso em 17 maio 2010.

ROSA, Alexandre Morais da. Revista IOB de direito penal e processo penal. Porto Alegre, ano 9, n. 50., jun/julh - 2008.

SALIBA, Marcelo Gonçalves. Justiça Restaurativa e paradigma punitivo. Curitiba: Juruá, 2009.

TAVARES, Mariana Marinho Barbalho. Revista do Ministério Público do estado do Rio Grande do Norte. Natal, ano 5. n. 7, jul/dez - 2005.

VEZZULLA, Juan Carlos. A mediação de conflitos com adolescentes autores de ato infracional. Florianópolis: Habitus, 2006. 